\title{
Erratum to: Retinal metabolic events in preconditioning light stress as revealed by wide-spectrum targeted metabolomics
}

\author{
Juan Manuel Chao de la Barca, ${ }^{1,2,4}$ - Nuan-Ting Huang ${ }^{4}$ Haihan Jiao ${ }^{4}$. \\ Lydie Tessier $^{2}$ - Cédric Gadras ${ }^{2}$ - Gilles Simard ${ }^{2,3} \cdot$ Riccardo Natoli $^{4,5}$. \\ Guillaume Tcherkez $^{6} \cdot$ Pascal Reynier $^{1,2} \cdot$ Krisztina Valter $^{4,5}$
}

Published online: 21 July 2017

(C) Springer Science+Business Media, LLC 2017

\section{Erratum to: Metabolomics (2017) 13:22 DOI 10.1007/s11306-016-1156-9}

The article was originally published Online First without open access. After publication in volume [13], issue [3], citation ID [22] the author decided to opt for Open Choice and to make the article an open access publication. Therefore, the copyright of the article has been changed to $\odot$ The Author(s) [2017] and the article is forthwith distributed under the terms of the Creative Commons Attribution 4.0 International License (http://creativecommons.org/licenses/ by/4.0/), which permits use, duplication, adaptation, distribution and reproduction in any medium or format, as long as you give appropriate credit to the original author(s) and the source, provide a link to the Creative Commons license and indicate if changes were made.

The online version of the original article can be found under doi:10.1007/s11306-016-1156-9.

Juan Manuel Chao de la Barca

jmchaodelabarca@chu-angers.fr

1 PREMMi/Pôle de Recherche et d'Enseignement en MédecineMitochondriale, Institut MITOVASC, CNRS 6214, INSERM U1083, Université d'Angers, 49933 Angers, France

2 Département de Biochimie et Génétique, Centre Hospitalier Universitaire, 4 rue Larrey, 49933 Angers cedex 9, France

3 INSERM U1063, Université d'Angers, 49933 Angers, France

4 Eccles Institute of Neuroscience, John Curtin School of Medical research, Australian National University, Canberra, ACT 2601, Australia

5 Medical School, Australian National University, Canberra, ACT 2601, Australia

6 Research School of Biology, College of Medicine, Biology and Environment, Australian National University, Canberra, ACT 2601, Australia 